(ISSN Cetak 1978-6573) (ISSN Online 2477-300X)

\title{
ANALISIS HUBUNGAN MOTIVASI TERHADAP KINERJA PEGAWAI PADA PT. POS INDONESIA CABANG BANDAR LAMPUNG
}

\author{
Ferry Diawanto \\ STKIP Kumala Lampung \\ ferry.diawanto@kumala.ac.id
}

\begin{abstract}
ABSTRAK
Penelitian in bertujuan untuk mengetahui hubungan motivasi terhadap kinerja pegawai pada PT. POS Indonesia Cabang Bandar Lampung. Hasil perhitungan antara variabel $\mathrm{X}$ terhadap variabel $\mathrm{Y}$ menggunakan uji statistic Product Moment diperoleh $r$ hitung sebesar 0.488 yang kemudian nilai $r$ hitung dikonsultasikan dengan tabel Product Moment pada $\mathrm{N}=42$ maka diperoleh keterangan bahwa $\mathrm{r}$ tabel 0.304 untuk taraf signifikan 5\% sedangkan untuk taraf signifikan 1\% adalah 0,393 sehingga $\mathrm{r}$ hitung lebih besar dari pada $\mathrm{r}$ tabel dibandingkan dengan batas signifikan. Bila $\mathrm{r}$ hitung sebesar 0,488 diinterpestasikan pada koefesien korelasi dengan indeks interprestasi berada pada nilai atau angka $0,400-0,599$ yang menyatakan nilai tersebut menunjukkan adanya korelasi sedang. Jadi tingkat hubungan variabel X dengan Y yakni Motivasi terhadap Peningkatan Kinerja Pegawai termasuk interval kategori sedang. Pengaruh dari Motivasi terhadap Peningkatan Kinerja Pegawai hanya mencapai $24 \%$, sedangkan pengaruh sebesar $76 \%$ berasal dari faktor lainnya. Kecilnya tingkat pengaruh dari X terhadap Y dikarenakan Motivasi (X) hanya merupakan salah satu faktor saja yang dapat mempengaruhi terhadap Peningkatan Kinerja Pegawai. Berdasarkan analisis tersebut, Sebaiknya PT. Pos Indonesia cabang Bandar lampung tetap mempertahankan dan meningkatkan motivasi kerja yang sudah baik agar kinerja pegawai dapat meningkat. Agar pekerjaan yang dikerjakan oleh pegawai menghasilkan kinerja yang optimal, maka pekerjaan tersebut harus memberikan kepuasan batin bagi para pekerja atau memotivasi pegawai secara intrinsik. Dan motivasi intrinsik ini mesti didesain dalam suatu lingkungan kerja sebagai program budaya perusahaan. Meskipun pegawai tetap membutuhkan motivasi eksternal seperti gaji untuk memenuhi pemuasan kebutuhannya.
\end{abstract}

Kata kunci: Motivasi, Kinerja Pegawai

\begin{abstract}
This study is aims to examine the effects of motivation toward the employee performance at PT. Pos Indonesia, branch of Bandar Lampung. The results of calculations between variables $\mathrm{X}$ to $\mathrm{Y}$ using the Product Moment statistical test obtained $r$ count of 0.488 which then the $r$ count value was consulted with the Product Moment table at $\mathrm{N}=42$ then obtained information that the $\mathrm{r}$ table 0.304 for a 5\% significant level while for a significant level of $1 \%$ is 0.393 so $r$ count is greater than $r$ table compared to the significant limit. If the $\mathrm{r}$ count of 0.488 is interpreted in the correlation coefficient with the interpretation index is at a value or number $0.400-0.599$ which states that the value indicates a moderate correlation. So, the level of relationship between variables $\mathrm{X}$ and $\mathrm{Y}$, namely Motivation to Increase Employee Performance including medium category intervals. The influence of motivation on employee performance improvement only reached $24 \%$, while the effect of $76 \%$ came from other factors. The small degree of influence of X on Y due to Motivation (X) is only one factor that can affect the Improvement of Employee Performance. Based on this analysis, it is recommended that PT. Pos Indonesia Bandar Lampung branch still maintain and increase good work motivation so that employee performance can improve. In order for the work done by employees to produce optimal performance, then the work must provide inner satisfaction for workers or intrinsically motivate employees. And this intrinsic motivation must be designed in a work environment as a corporate
\end{abstract}


culture program. Although employees still need external motivation such as salary to meet the satisfaction of their needs.

Keywords: Motivation, Employee Performance

\section{PENDAHULUAN}

Keberadaan sumber daya manusia di dalam suatu perusahaan memegang peranan sangat penting. Tenaga kerja memiliki potensi yang besar untuk menjalankan aktivitas perusahaan. Potensi setiap sumber daya manusia yang ada dalam perusahaan harus dapat dimanfaatkan sebaik-baiknya, sehingga mampu memberikan hasil yang maksimal.

Perusahaan dan pegawai merupakan dua hal yang saling membutuhkan. Jika pegawai berhasil membawa kemajuan bagi perusahaan, keuntungan yang diperoleh akan dipetik oleh kedua belah pihak. Bagi pegawai, keberhasilan merupakan aktualisasi potensi diri sekaligus peluang untuk memenuhi kebutuhan hidupnya. Sedangkan bagi perusahaan, keberhasilan merupakan sarana menuju pertumbuhan dan perkembangan perusahaan.

Seiring dengan perkembangannya, perusahaan sering kali mengabaikan tentang pengelolaan sumber daya manusia yang dimilikinya. Kendati sering terdengar isu tentang pentingnya pengelolaan sumber daya manusia di lingkungan perusahaan, tetapi penanganannya secara terencana dan terfokus, baik oleh perusahaan maupun individu sebagai pegawai itu sendiri jarang dilakukan.

Sementara itu dunia pada saat ini sedang menghadapi dua tantangan utama. Pertama, perubahan lingkungan/iklim bisnis yang cepat diiringi dengan meningkatnya kualitas dan kebutuhan konsumen. Dari satu sisi perubahan yang cepat itu mengakibatkan terjadinya dinamika pekerjaan berupa perubahan dan perkembangan yang menuntut keterampilan dan keahlian yang melebihi dari sebelumnya. Dari sisi lain ternyata keinginan dan kebutuhan konsumen bukanlah suatu yang statis, tetapi terus berkembang secara dinamis pula. Konsumen selalu mendambakan keinginan dan kebutuhan dapat terpenuhi secara berkualitas dan memuaskan. Kedua, meningkatnya persaingan antara perusahaan mengharuskanya setiap perusahaan untuk menjalankan kegiatan operasionalnya dengan cara yang lebih efisien, efektif dan produktif.

Untuk menghadapi tantangan utama ini, maka perusahaan perlu untuk menuntut kinerja pegawai yang tinggi dari pegawainya, dimana kinerja pegawai yang diharapkan tersebut salah satunya dipengaruhi oleh motivasi. Menurut Hasibuan (1990:156), "Motivasi adalah hal yang menyebabkan, menyalurkan dan mendukung perilaku manusia supaya mau bekerja giat dan antusias mencapai hasil yang maksimal."

Setiap pegawai mempunyai perbedaan individual sebagai akibat dari latar belakang pendidikan, pengalaman, dan lingkungan masyarakat yang beraneka ragam maka hal ini akan terbawa ke dalam pekerjaannya, sehingga akan mempengaruhi sikap dan tingkah laku pegawai tersebut dalam melaksanakan pekerjaannya. Di samping itu suasana batin/psikologis seseorang secara individu dalam organisasi yang memiliki lingkungan kerjanya, sangat besar pengaruhnya terhadap pelaksanaan kerjanya. Hal ini berarti pegawai memerlukan motivasi kerja yang kuat agar bersedia melaksanakan pekerjaan secara bersemangat, berkinerja pegawai tinggi dan produktif. 
Untuk memahami konsep motivasi lebih lanjut, Lyman Porter dan Raymond Miles mengemukakan suatu pandangan sistem mengenai motivasi. Menurut James A. F. Stoner dan R. Edward Freeman (1994:431) yang mengutip pendapat dari Lyman dan Raymond Miles, pendekatan ini sangat berguna bagi manajer dalam memahami konsep motivasi sehingga dapat memotivasi pegawai secara tepat agar kinerja pegawai meningkat. Pandangan sistem ini membahas seluruh rangkaian kekuatan sistem yang beroperasi pada pegawai, yang harus dipertimbangkan sebelum motivasi dan perilaku pegawai dapat dipahami secara memadai.

Lyman Porter dan Raymond Miles menjelaskan bahwa sistem motivasi mencakup tiga faktor karakteristik yang meliputi timbulnya motivasi pegawai. Ketiga karakteristik tersebut adalah karakteristik individu, karakteristik pekerjaan dan karakteristik situasi kerja (Stoner, 1986:87). Sistem motivasi ini digunakan karena perspektif sistem dari motivasi ini merupakan yang paling berguna bagi perusahaan untuk mengetahui motivasi kerja pegawai.

Karakteristik individu terdiri atas minat, sikap dan kebutuhan yang dibawa seseorang ke tempat kerjanya. Karakteristik pekerjaan merupakan sikap. Tugas pegawai yang meliputi jumlah tanggung jawab, macam tugas, dan tingkat kepuasan yang diperoleh dari pekerjaan itu sendiri. Sedangkan karakteristik situasi kerja atau organisasi terdiri dari dua hal, yaitu lingkungan kerja terdekat dan tindakan organisasi sebagai satu kesatuan.

Penggunaan tenaga kerja yang efektif dan terarah merupakan kunci dari peningkatan kinerja pegawai sehingga dibutuhkan suatu kebijaksanaan perusahaan untuk menggerakkan tenaga kerja tersebut agar mau bekerja lebih produktif, sesuai dengan rencana yang telah direncanakan oleh perusahaan.
Salah satu faktor yang dapat meningkatkan kinerja pegawai adalah dengan cara memberi motivasi kepada pegawai.

Kinerja pegawai merupakan kebutuhan bagi pegawai, hal ini sebagai mana pendapat Mc. Clelland dalam Stoner (1986:14) yang menunjukkan bahwa motif yang kuat berkinerja pegawai untuk berhasil atau unggul dalam situasi persaingan berhubungan dengan sejauh mana motivasi yang dimiliki individu untuk menjalankan tugas-tugasnya.

Berdasarkan pokok pemikiran di atas, maka sangat jelas bahwa faktor motivasi memiliki peranan penting yang mempengaruhi kinerja pegawai dalam perusahaan. Hal ini disebabkan motivasi kerja yang mempengaruhi oleh tiga karakteristik di atas akan membawa perilaku bagi pegawai.

\section{METODE PENELITIAN}

Dalam penelitian ini penulis memakai sifat penelitian deskriptif kuantitatif, karena penelitian ini bersifat deskriptif penjabaran atau memaparkan suatu kejadian yang ada pada masa lalu dan sekarang, sebagaimana dinyatakan bahwa: "Penelitian diskriptif bertujuan pada pemecahan masalah yang ada pada masa sekarang."

\section{A. Deskripsi Data tentang Motivasi}

Data mengenai motivasi diperoleh dari responden sebanyak 42 orang, dengan angket sebagai alat pengumpulan datanya. Didalam angket yang disebarkan kepada responden terdapat lima alternatif jawaban yang disusun secara bertingkat, yaitu:

1. Alternatif jawaban a berarti sangat baik dengan nilai skor 5

2. Alternatif jawaban b berarti baik dengan nilai skor 4

3. Alternatif jawaban c berarti cukup baik dengan nilai skor 3 
4. Alternatif jawaban d berarti kurang baik dengan nilai skor 2

5. Alternatif jawaban e berarti sangat tidak baik dengan nilai skor 1

Untuk mengetahui tentang Motivasi pada PT. Pos Indonesia Cabang Bandar Lampung ini diajukan 10 buah pertanyaan kepada seluruh responden sebagai wakil dari populasi. Data mengenai Motivasi ini menunjukkan bahwa PT. Pos Indonesia Cabang Bandar Lampung masuk kedalam kategori baik. Seperti terlihat dari data dalam Tabel 1 berikut:

Tabel I. Distribusi Tanggapan Responden tentang Motivasi (Variabel X)

\begin{tabular}{|c|c|c|c|c|c|c|}
\hline \multirow{2}{*}{$\begin{array}{c}\text { Nomor } \\
\text { Angket }\end{array}$} & \multicolumn{5}{|c|}{ Jawaban Responden } & \multirow{2}{*}{ Jumlah } \\
\cline { 2 - 6 } & $\mathbf{A}$ & $\mathbf{B}$ & $\mathbf{C}$ & $\mathbf{D}$ & $\mathbf{E}$ & \\
\hline 1 & 15 & 21 & 6 & 0 & 0 & 42 \\
\hline 2 & 6 & 24 & 12 & 0 & 0 & 42 \\
\hline 3 & 5 & 26 & 9 & 2 & 0 & 42 \\
\hline 4 & 11 & 23 & 6 & 2 & 0 & 42 \\
\hline 5 & 8 & 26 & 7 & 1 & 0 & 42 \\
\hline 6 & 10 & 29 & 2 & 1 & 0 & 42 \\
\hline 7 & 9 & 27 & 6 & 0 & 0 & 42 \\
\hline 8 & 7 & 26 & 7 & 2 & 0 & 42 \\
\hline 9 & 6 & 29 & 7 & 0 & 0 & 42 \\
\hline 10 & 6 & 31 & 5 & 0 & 0 & 42 \\
\hline \multirow{2}{*}{$\begin{array}{c}\text { Total } \\
\text { Persentase }\end{array}$} & $\mathbf{8 3}$ & $\mathbf{2 6 2}$ & $\mathbf{6 7}$ & $\mathbf{8}$ & $\mathbf{0}$ & $\mathbf{4 2 0}$ \\
\cline { 2 - 6 } & $\mathbf{1 9 . 7 6} \%$ & $\mathbf{6 2 . 3 8 \%}$ & $\mathbf{1 5 . 9 5 \%}$ & $\mathbf{1 . 9 0 \%}$ & $\mathbf{0 . 0 0} \%$ & $\mathbf{1 0 0 . 0 0 \%}$ \\
\hline
\end{tabular}

Sumber: Diolah Peneliti (2019)

Berdasarkan data dalam tabel 6 di atas, terlihat bahwa tingkat Motivasi (Variabel X) pada PT. Pos Indonesia Cabang Bandar Lampung termasuk kategori Baik, hal ini ditunjukkan oleh persentase jawaban sebesar $62.38 \%$ responden yang menjawab alternatif jawaban B.

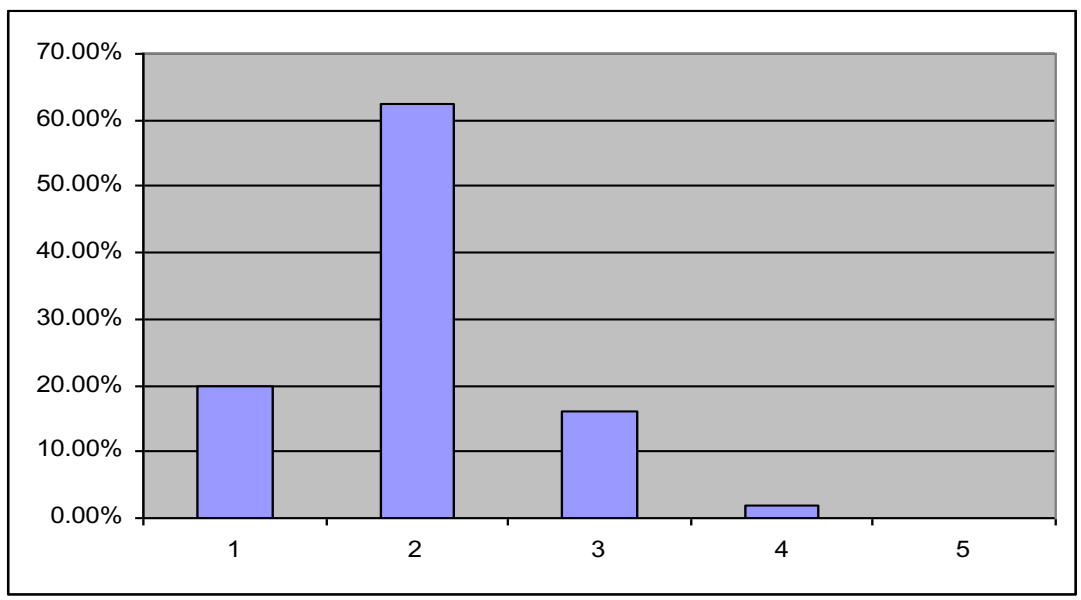

Gambar 1. Grafik Frekuensi Motivasi 
Jelaslah bahwa Motivasi berada dalam posisi baik, hal ini ditunjukkkan perolehan lebih dari separuh responden yakni $62.38 \%$. Sedangkan yang bependapat bahwa Motivasi cukup baik adalah sebanyak $15.95 \%$, dan $19.76 \%$ justru berpendapat bahwa Motivasi-nya sangat baik. Dalam hal ini yang menjawab bahwa motivasi Kurang
Baik sebanyak 1,90\% dari jumlah responden.

B. Deskripsi Data tentang Meningkatkan Kinerja Pegawai

Data tentang tanggapan responden mengenai Peningkatan Kinerja Pegawai, dikemukakan dalam Tabel 2 berikut ini:

Tabel 2. Distribusi Jawaban Responden tentang Meningkatkan Kinerja Pegawai (Variabel Y)

\begin{tabular}{|c|c|c|c|c|c|c|}
\hline \multirow{2}{*}{$\begin{array}{c}\text { Nomor } \\
\text { Angket }\end{array}$} & \multicolumn{5}{|c|}{ Jawaban Responden } & \multirow{2}{*}{ Jumlah } \\
\cline { 2 - 6 } & $\mathbf{A}$ & $\mathbf{B}$ & $\mathbf{C}$ & $\mathbf{D}$ & $\mathbf{E}$ & \\
\hline 21 & 14 & 26 & 2 & 0 & 0 & 42 \\
\hline 22 & 16 & 22 & 3 & 1 & 0 & 42 \\
\hline 23 & 14 & 26 & 2 & 0 & 0 & 42 \\
\hline 24 & 12 & 25 & 4 & 1 & 0 & 42 \\
\hline 25 & 16 & 22 & 4 & 0 & 0 & 42 \\
\hline 26 & 13 & 27 & 2 & 0 & 0 & 42 \\
\hline 27 & 14 & 20 & 7 & 1 & 0 & 42 \\
\hline 28 & 15 & 26 & 1 & 0 & 0 & 42 \\
\hline 29 & 9 & 27 & 6 & 0 & 0 & 42 \\
\hline 30 & 11 & 30 & 1 & 0 & 0 & 42 \\
\hline Total & $\mathbf{1 3 4}$ & $\mathbf{2 5 1}$ & $\mathbf{3 2}$ & $\mathbf{3}$ & $\mathbf{0}$ & $\mathbf{4 2 0}$ \\
\cline { 2 - 6 } Persentase & $\mathbf{3 1 . 9 0 \%}$ & $\mathbf{5 9 . 7 6 \%}$ & $\mathbf{7 . 6 2 \%}$ & $\mathbf{0 . 7 1 \%}$ & $\mathbf{0 \%}$ & $\mathbf{1 0 0 \%}$ \\
\hline
\end{tabular}

Sumber: Diolah Peneliti (2019)

Dari tabel 7 di atas, terlihat bahwa responden sebanyak 59,76\% memilih jawaban B dalam angket yang disebarkan oleh peneliti. Hal ini berarti peningkatan Kinerja Pegawai berjalan dengan baik.
Data mengenai peningkatan Kinerja Pegawai ini jika ditampilkan dalam bentuk grafiknya seperti dibawah ini: 


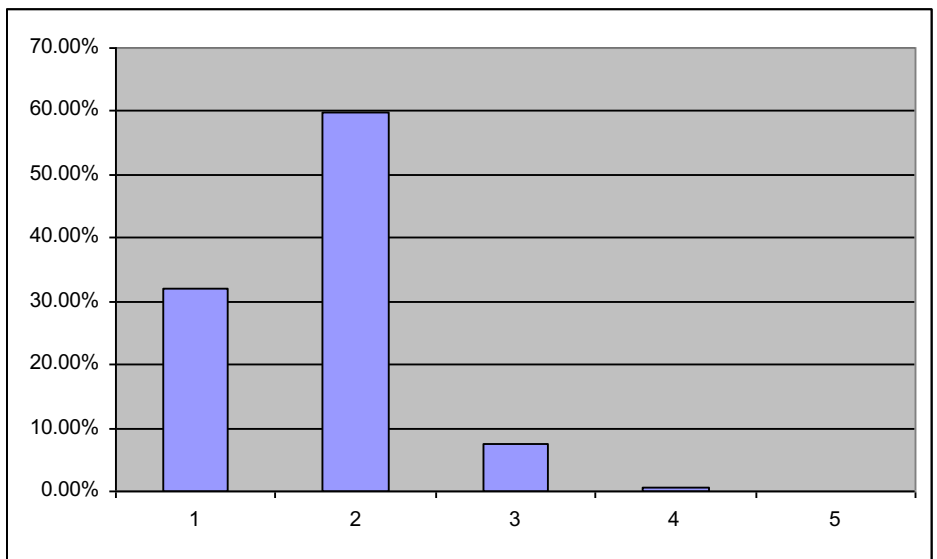

Gambar 2. Grafik Frekuensi Kinerja Pegawai

Kemudian apabila dilihat berdasarkan grafik diatas, maka diketahui bahwa $31,90 \%$ dari responden memilih jawaban A dalam angket yang diberikan pada responden. Sedangkan 7,62\% responden memilih jawaban $\mathrm{C}$ dalam angket yang berarti bahwa Kinerja Pegawai sedang saja dalam pelaksanaannya, walaupun telah diberi dorongan motivasi dari pimpinan, kemudian $0,71 \%$ responden memilih jawaban $\mathrm{D}$ ini berarti masih kurangnya Kinerja Pegawai. Dalam menjawab pertanyaan tentang Kinerja Pegawai ini, tidak ada satu orang pun yang memilih jawaban $E$ dalam angket yang di berikan kepada responden.

\section{HASIL DAN PEMBAHASAN}

A. Korelasi Antara (X1) dengan Variabel Pengembangan Kinerja Pegawai (Y)

Prosedur ini digunakan untuk mengetahui atau ingin mencari hubungan antara Variabel Pendidikan (X) dengan Variabel Pengembangan Kinerja Pegawai (Y) dengan menggunakan Metode Pearson Product Moment. Adapun dalam pengolahan SPSS diperoleh output sebagai berikut:

Tabel 3. Analisis Output

Descriptive Statistics

\begin{tabular}{|l|r|r|r|}
\hline & \multicolumn{1}{|c|}{ Mean } & Std. Deviation & $\mathrm{N}$ \\
\hline Motivasi (X) & 40.00 & 2.153 & 42 \\
Kinerja (Y) & 42.29 & 2.482 & 42 \\
\hline
\end{tabular}

Sumber: Diolah Peneliti (2019)

Dari output diperoleh informasi sebagai berikut:

Mean dari Motivasi

Mean dari Kinerja

Standard Deviation Motivasi

$$
=40,00
$$$$
=42,29
$$$$
=2,153
$$ 
(ISSN Cetak 1978-6573) (ISSN Online 2477-300X)

Standard Deviation Kinerja

Banyaknya data yang dianalysis

$$
=2,482
$$$$
=42
$$

Berdasarkan data hitungan tersebut diatas, maka diketahui nilai rata-rata Variabel Motivasi (X) sebesar 40,00, hal ini termasuk dalam kategori baik. Kemudian diketahui nilai rata-rata dari Variabel Kinerja (Y) sebesar 42,29, nilai tersebut dapat dikategori baik.

Selanjutnya berdasarkan hasil perhitungan SPSS diatas maka diketahui nilai Standard Deviation untuk Motivasi sebesar 2,153 dan nilai Standard Deviation Kinerjanya sebesar 2,482, hal ini menggambarkan nilai Standard Deviation untuk Kinerja lebih besar banding Motivasi. Dengan demikian maka jawaban untuk variabel kinerja lebih bervariasi dibanding dengan variabel Motivasi.

Tabel 4. Tabel 5. Output Metode Pearson Product Moment Correlations

\begin{tabular}{|c|c|c|c|}
\hline & & Motivasi (X) & Kinerja $(Y)$ \\
\hline \multirow[t]{5}{*}{ Motivasi (X) } & Pearson Correlation & 1 & $.488^{* \prime}$ \\
\hline & Sig. (2-tailed) & & .001 \\
\hline & $\begin{array}{l}\text { Sum of Squares and } \\
\text { Cross-products }\end{array}$ & 190.000 & 107.000 \\
\hline & Covariance & 4.634 & 2.610 \\
\hline & $\mathrm{N}$ & 42 & 42 \\
\hline \multirow[t]{5}{*}{ Kinerja $(\mathrm{Y})$} & Pearson Correlation & $.488^{* *}$ & 1 \\
\hline & Sig. (2-tailed) & .001 & \\
\hline & $\begin{array}{l}\text { Sum of Squares and } \\
\text { Cross-products }\end{array}$ & 107.000 & 252.571 \\
\hline & Covariance & 2.610 & 6.160 \\
\hline & $\mathrm{N}$ & 42 & 42 \\
\hline
\end{tabular}

${ }^{* *}$. Correlation is significant at the 0.01 level (2-tailed).

Sumber: Diolah Peneliti (2019)

Dengan menggunakan korelasi Pearson diperoleh $r=0,488$. itu berarti hubungan antara Motivasi dengan Kinerja bila dikonsultasikan dengan tabel 1 berada antara interval $0,400-0,599$ dengan tingkat hubungan antar variabel Sedang.
1. Koefesien Diterminasi

Selanjutnya

untuk menyatakan besar kecilnya sumbangan variabel Motivasi (X) terhadap variabel Kinerja (Y) digunakan dengan rumus koefesien diterminan sebagai berikut:

$$
\begin{array}{ll}
\mathbf{K P} & =0,488^{2} \times 100 \% \\
\mathbf{K P} & =23,8 \% \approx 24 \% \\
\mathbf{K P} & =r^{2} \times 100 \%
\end{array}
$$


Berdasarkan Uji statistik tersebut maka besarnya kontribusi dari Motivasi terhadap kinerja hanya mencapai $24 \%$. Sedangkan sisanya sebesar $76 \%$ berasal dari faktor lain yang tidak diteliti dalam penelitian ini. Kecilnya tingkat pengaruh dari $\mathrm{X}$ terhadap $\mathrm{Y}$ karena variabel $\mathrm{X}$ hanya merupakan salah satu faktor yang memberikan kontribusi terhadap peningkatan kinerja pegawai pada P.T. Pos

$$
\begin{aligned}
& t=r \sqrt{\frac{n-2}{1-r^{2}}} \\
& t=0,488 \sqrt{\frac{42-2}{1-0,488^{2}}} \\
& t=3,540
\end{aligned}
$$

Telah diketahui bahwa harga $t$ Hitung sebesar 3,540 ini selanjutnya dikonsultasikan dengan harga $t$ Tabel dengan taraf signifikan 5\% dan Dk $42-2=40$, karena didalam $\mathrm{t}$ Table terdapat nilai Dk 40, nilai Dk berdasarkan dengan Dk 40, maka diketahui nilai distribusi t tabelnya adalah 1,684. Ternyata $t$ Hitung lebih besar dari t Tabel atau 3,540 > 1,684 dengan demikian maka Korelasi Pearson yang ditemukan signifikan / nyata.

Dengan melihat hasil analisa diatas, dapat ditarik suatu kesimpulan bahwa benar terbukti adanya hubungan yang positif dan signifikan antara variabel motivasi (X) terhadap variabel Kinerja (Y). maka Hipotesis Positif $\left(\mathrm{H}_{1}\right)$ yang diajukan dapat diterima dan Hipotesis Negatif $\left(\mathrm{H}_{0}\right)$ yang ditolak.

\section{KESIMPULAN}

Indonesia Cabang Bandar Lampung.

2. Pengujian Hipotesis Korelasi

Kemudian berdasarkan uji statistic diatas, untuk mengetahui apakan hipotesis yang diajukan dapat diterima atau tidak akan maka akan dihitung menggunakan uji t, dengan menggunakan $\alpha=$ 0,05 maka statistic uji $t$ yang dimaksud adalah sebagai berikut:

Setelah diadakan analisis pada data yang ada pada penelitian ini, maka penulis dapat menyimpulkan sebagai berikut: Bahwa ada hubungan yang positif dan signifikan antara factor Motivasi terhadap faktor Peningkatan Kinerja Pegawai pada P.T. Pos Indonesia Cabang Bandar Lampung.

Hasil perhitungan antara variabel $\mathrm{X}$ terhadap variabel $\mathrm{Y}$ menggunakan uji statistic Product Moment diperoleh $r$ hitung sebesar 0,488 yang kemudian nilai $\mathrm{r}$ hitung dikonsultasikan dengan tabel Product Moment pada $\mathrm{N}=42$ maka diperoleh keterangan bahwa $\mathrm{r}$ tabel 0,304 untuk taraf signifikan 5\% sedangkan untuk taraf signifikan $1 \%$ adalah 0,393 sehingga $r$ hitung lebih besar dari pada $r$ tabel dibandingkan dengan batas signifikan.

Bila $r$ hitung sebesar 0,488 diinterpestasikan pada koefesien korelasi dengan indeks interprestasi berada pada nilai atau angka $0,400-0,599$ yang menyatakan nilai tersebut menunjukkan adanya korelasi sedang. Jadi tingkat hubungan variabel $\mathrm{X}$ dengan $\mathrm{Y}$ yakni 
Motivasi terhadap Peningkatan Kinerja Pegawai termasuk interval katagori sedang.

$$
\begin{array}{rlrrr}
\mathrm{KP} & =\mathrm{r}^{2} & \mathrm{X} & 100 \% \\
& =0,488^{2} & \mathrm{X} & 100 \% \\
& =24 \% & &
\end{array}
$$

Dengan demikian berarti pengaruh dari Motivasi terhadap Peningkatan Kinerja Pegawai hanya mencapai 24\%, sedangkan pengaruh sebesar $76 \%$ berasal dari faktor lainnya. Kecilnya tingkat pengaruh dari $\mathrm{X}$ terhadap $\mathrm{Y}$ dikarenakan Motivasi (X) hanya merupakan salah satu faktor saja yang dapat mempengaruhi terhadap Peningkatan Kinerja Pegawai.

Apabila hasil uji statistic Product moment tersebut dihitung menggunakan uji t, maka diketahui harga $t$ hitung sebesar 3,540. selanjutnya dikonsultasikan dengan harga $\mathrm{t}$ table dengan taraf signifikan 5\% dan Dk 40 didapatkan nilai $\mathrm{t}$ table sebesar 1,684. Ternyata $t$ hitung lebih besar dari t table atau 3,540 $>1,684$.

Dengan demikian dapat ditarik kesimpulan bahwa terdapat hubungan yang positif dan signifikan antara variel $\mathrm{X}$ terhadap variabel $\mathrm{Y}$, dan hipotesis positif yang diajukan (Ha) dapat diterima dan hipotesis negatif (Ho) yang ditolak.

\section{DAFTAR PUSTAKA}

Arikunto, S. (1998). Prosedur Penelitian. Jakarta: Rineka Cipta.

Dessler, Garry dalam Agus D. (1986). Organisasi dan Manajemen. new Jersley: Prentice Hall Inc.

Hasibuan, S.P, Melayu. (1992). Manajemen Sumber Daya Manusia, Dasar dan Kunci Keberhasilan. Jakarta: C.V. Haji Masagung.

Lathan, P.G., \& Wexley, N.K. (1982). Increasing Productivity through Performance Appraisal. Sydney:
Kemudian jika diuji dengan rumus KP maka hasilnya adalah sebagai berikut:

Adisoan Wesley Publishing
Company.

Manullang. (1981). Manajemen Personalia. Jakarta: Ghalia.

Maslow, A.H. (1979). A Theory of Human Motivation. Jakarta: Balai Akbar.

Riduwan. (1992). Pengantar Statistika untuk Penelitian. Bandung: Alfa Beta.

Siagian, P.S. (1992). Manajemen Sumber Daya Manusia. Jakarta: Bumi Aksara.

Sugiono. (2001). Metode Penelitian Administrasi. Bandung: Alfa Beta.

Sugiono. (2003). Statistik untuk Penelitian. Bandung: Alfa Beta.

Wahjosumidjo. (1984). Kepemimpinan dan Motivasi. Jakarta: Ghalia Indonesia. 